\title{
Atendimento préhospitalar ao idoso vítima de violência em cinco capitais brasileiras
}

\author{
Pre-hospital attendance to elders victims of violence \\ in five Brazilian capitals
}

Suely Ferreira Deslandes ${ }^{1}$

Edinilsa Ramos deSouza ${ }^{2}$

${ }^{1}$ Departamento deEnsino, Instituto Fernandes Figueira, Fundação O swaldo Cruz. Av. Rui Barbosa, 716/ 20 andar. Flamengo 22250-020 Rio de Janeiro RJ. desland@iff.fiocruz.br ${ }^{2}$ Centro Latino-Americano de Estudos sobre Violência e Saúde Jorge Careli, Escola Nacional deSaúde Pública Sergio Arouca, Fundação Oswaldo Cruz.
Abstract This article reviews the characteristics and operation in the daily routine of a pre-hospital care to the elderly victims of violence and accidents in five capitals ( $M$ anaus, Recife, Brasília, Rio de Janeiro and Curitiba). Besides that, it analyses their abilities, and potential obstacles. It was based on thetriangulation of quantitativeand qualitative methods analyzing data from $80 \mathrm{de}$ partments of mobile and fixed pre hospitals: 32 in Manaus, 18 in Recife, 10 in Brasilia, 12 in Rio de Janeiro and eight in Curitiba. Among the findings are the differences in size and diversity of occupational categories and difficulties of the teams to identify, serve and report cases for lack of training, limited preventive action, almost no involvement and guidance to the family, practically no attention to the perpetrator; incipient articulation and partnership network, especially regarding on pre hospital services and the hospital.

Key words Pre-hospital care, Elderly victims of violence and accidents, Preventive action
Resumo Este artigo analisa as características e a operacionalização no cotidiano da atenção pré hospitalar aos idosos vítimas de violências e acidentes de cinco capitais (M anaus, Recife, Brasília, Rio de Janeiro e Curitiba), abordando ainda suas capacidades, seus obstáculose potencialidades. Pautou-se na triangulação de métodos quantitativos e qualitativos. A nalisaram-se dados de oitenta serviços da atenção pré-hospitalar móvel e fixa: 32 em Manaus; 18 em Recife; dez em Braślia; 12 no Rio de Janeiro e oito em Curitiba. Entre os achados estão as diferenças (de tamanho e diversidade decategoriasprofissionais) edificuldades das equipes para identificar, atender e notificar os casos por falta de capacitação; pouca atuação preventiva; quase nenhum envolvimento com a família e orientação a ela; praticamente nenhum atendimento ao autor da agressão; incipiente articulação e parcerias da rede, sobretudo dos servi ços pré hospitalares com os hospitalares.

Palavras-chave Préhospitalar, Idosos, Violência, Acidentes de trânsito, Prevenção 
Introdução

0 atendimento pré-hospitalar no Brasil é composto pelas instâncias fixa e móvel e apresenta enorme diversidade de serviços com distintos papéis e formas organizacionais.

0 "pré-hospitalar móvel" objetiva atender precocementeaos problemas denatureza clínica, cirúrgica, psiquiátrica e traumática, prestando atendimento ou transporte a um serviço de saúde hierarquizado e integrado ao Sistema Ú nico de Saúde (SUS). D eve estar ligado a uma central deregulação, com equipe efrota de veículos ade quados às necessidades de saúde do município ou da região ${ }^{1}$.

Em alguns municípios, o Corpo de Bombeiros é o responsável pelo atendimento móvel às pessoas envolvidas em acidentes eviolências. Em outros, duas modalidades de socorro são coadjuvantes na atenção prestada às vítimas: Serviço de Atendimento Móvel de Urgência (Samu) e Bombeiros. Existem ainda modelos de resgate diferenciados, ligados às municipalidades, tais como serviços privados relacionados às concessionárias que administram rodovias.

No Brasil vigora o Samu-192, oficializado pela Portaria $n^{\circ} 1.864 / \mathrm{GM}^{2}$, que institui o componente pré-hospitalar móvel da Política Nacional de Atenção às Urgências, por intermédio da sua implantação no território brasileiro. Nessa portaria, a regulação médica das urgências deve ser regionalizada, hierarquizada, descentralizada, pactuada, ter a participação da comunidade eatender aos princípios da integralidade, da universalidade e da equidade.

A central deve dispor de tel efone gratuito. 0 número 192 foi nacionalmente adotado para urgências médicas. Um médico regulador monitora 0 atendimento local via rádio, estabelecendose uma rede de comunicação entre a central, as ambulâncias e os serviços que recebem os pacientes. Os serviços de segurança e salvamento também devem ser orientados por esse médico.

0 "pré-hospitalar fixo" atende aos quadros agudos, de natureza clínica, traumática ou psiquiátrica, com baixagravidade/complexidade, da área de cobertura dos serviços que são heterogêneos, como: Unidades Básicas de Saúde (UBS), unidades do Programa/Estratégia Saúde da Família e de Agentes Comunitários de Saúde (Pacs), ambulatórios especializados, serviços de diagnóstico eterapia, pronto atendimento (PA) de 24 horas, também denominado pronto-socorro (OS).

0 atendimento préhospitalar móvel ou fixo parte da premissa de que lesões e traumas provocados por acidentes eviolências podem ser reverti- dos, dependendo do suporte oferecido à vítima. A qualidade e a presteza do atendimento às vítimas de trauma são fundamentais para o prognóstico ${ }^{3}$.

Este artigo analisa as capacidades, os obstáculos e as potencialidades da atenção dispensada aos idosos vítimas de violências e acidentes pelo sistema pré-hospitalar de cinco capitais. Retoma as diretrizes de um estudo anterior ${ }^{4}$ que realizou análise crítica da institucionalização da Política Nacional de Redução da M orbimortalidade por Acidentes e Violências (PN RM AV) nessas mesmas capitais.

\section{Metodologia}

Tomou-se como base a pesquisa multicêntrica realizada em M anaus, Recife, Braślia, Rio de Janeiro e Curitiba, desenvolvida em 2007/2008, que usou abordagem quantitativa e qualitativa objetivando uma análise diagnóstica dos sistemas locais de saúde, para atender aos agravos provocados por acidentes e violências contra idosos.

A pesquisa original usou como parâmetros analíticos 0 que é preconizado pelas principais políticas de atenção à saúde e proteção dos direitos da pessoa idosa: Política Nacional do Idoso, Política Nacional de Saúde do Idoso e o Estatuto do Idoso; as Políticas de Atenção à Saúde M ental, a de Atenção às Emergências, o Pacto pela Saúde, a Política de Reabilitação e a Política Nacional de Redução da M orbimortalidade por Acidentes e Violências.

O estudo pautou-se na triangulação de métodos. U saram-se dois questionários semiestruturados: um para caracterizar os serviços eoutro para qualificar seu atendimento. Foram feitas entrevistas individuais com profissionais e gestores de saúde das unidades pesquisadas aprofundando a reflexão sobre obstáculos e potencialidades da atenção dispensada aos idosos vítimas de violências e acidentes. Este artigo considera os dados de oitenta serviços relativos à atenção pré-hospitalar móvel efixo: 32 em M anaus; 18 em Recife; dez em Braślia; 12 no Rio de Janeiro e oito em Curitiba. Envolveu 15 unidades do Programa/Estratégia Saúde da Família (PSF), 22 de Atenção Básica Ampliada (ABA), 22 prontos-socorros (PS)/ pronto atendimento (PA) 24 horas; 15 ambulatórios especial izados e seis unidades pré- hospitalares móveis (PH móvel). 0 acervo analisado constitui-se de oitenta questionários e 27 entrevistas com gestores, médicos, socorristas e coordenadores de unidades de referência para idoso.

Os dados dos questionários foram digitados em um banco no programa CSPro versão 3.2 e 
convertidos para o SPSS versão 13.0, no qual foram analisados em termos absolutos e relativos. Às entrevistas aplicou-se a análise de conteúdo, segundo a modalidade temática adaptada de Bardin ${ }^{5}$, sendo procedidas leitura flutuante, análise dos temas, categorização teórica eêmica, destaques dos núcleos de sentido, descrição dos conteúdos e síntese interpretativa.

Para verificar se a aten ção prestada pelos serviços de saúde cumpria as diretrizes preconizadas, foram construídos e validados indicadores de avaliação, segundo a técnica Grupo Nominal ${ }^{6,7}$, que visa à geração de consenso e caracteriza-se pela presença de sujeitos num encontro coletivo, quando os participantes relatam por escrito suas opiniões e propostas, que são discutidas com o grupo. Foram reunidos especialistas ligados ao atendimento pré-hospitalar em todas as capitais envolvidas no estudo.

\section{Resultados}

\section{Caracterização \\ do serviço pré-hospitalar móvel}

$N$ as capitais estudadas antes da chegada do Samu, exceto Rio de Janeiro eCuritiba, o resgate não se caracterizava como socorro médico; era realizado por ambulâncias do Corpo de Bombeiros com o apoio de um socorrista profissional de saúde de nível técnico e um motorista.

Em M anaus, o resgate dos Bombeiros era complementado pelo serviço municipal SOS $M$ anaus, assistido por técnicos de enfermagem. Possuía considerável número de viaturas (segundo um gestor, a frota chegava a quarenta ambulâncias). Atualmente este serviço desempenha o papel de SOS Social, realizando o transporte de pacientes crônicos para tratamento na rede hospitalar, inclusive idosos.

O Samu cobria sete bases em M anaus. Contava em 2006 com equipe mais multiprofissional que as demais cidades: 41 enfermeiros, quatro odontólogos, um farmacêutico, 141 técnico/auxiliares de enfermagem e dois psicólogos. Esse serviço não informou com quantos médicos contava. H avia uma divisão de tarefas diferenciadas de "resgate" e "socorro". Os Bombeiros atuavam no resgate de vítimas em situações que demandam ações de busca e salvamento ou específicas (afogamento, indivíduo preso em ferragens etc.) e o Samu só era acionado em seguida.

Em Recife, o gestor considerou a implantação do Samu incompleta, pois o Corpo de Bombeiros atuava com legislação própria, sem ser regu- lado pelo Serviço de Atendimento M óvel de Urgência. Contudo, atualmente os dois serviços são parcerias, utilizando um sistema conectado de chamadas e dividindo as tarefas segundo a demanda: o socorro às situações de trauma em locais e condições de difícil acesso à vítima cabe aos Bombeiros, eas situações clínicas e de trauma são atendidas pelo Samu (nas residências ou vias públicas). O Serviço de Atendimento M óvel de Urgência contava com 56 médicos, 21 enfermeirose oitenta técnicos/auxiliares deenfermagem.

Em Brasília, as atribuições dos dois serviços eram as mesmas das demais capitais. 0 Samu desta cidade possuía a maior equipe: 105 médicos, 88 enfermeiros e 320 técnicos/auxiliares de enfermagem.

Curitiba trabalha desde 1990 de maneira integrada por meio do Serviço de Atendimento ao Trauma em Emergência (Siate), numa parceria entre as Secretarias M unicipal eEstadual de Saúde e a Secretaria Estadual de Segurança Pública. Esse serviço atua com regulação médica, atendendo às vítimas de traumas. Trabalha com a linha 192 para as causas clínicas (Samu) e a 193 para as causas externas (Corpo de BombeirosSiate). 0 Samu incorporou o Siate, respeitando a autonomia de cada instituição. Assim, apoiados pela regulação médica do Samu, os Bombeiros atendem a maior parte dos traumas. Os dois serviços contavam com a menor equipe dentre as cidades estudadas: 95 médicos, 36 enfermeiros e 50 técnicos/auxiliares de enfermagem.

O Rio de Janeiro apresentava situação sui ge neris. Desde 1986, o Corpo de Bombeiros atua com equipes médicas eéresponsável pelo socorro e resgate. Com o Samu, cindiram-se as atribuições ${ }^{4}$. Posteriormente, o Governo do Estado unificou os serviços, sob coordenação do Corpo de Bombeiros na Secretaria de Saúde e Defesa Civil, unificada em 2007. 0 gestor do GSE (Bombeiros) assumiu a Superintendência deU rgências eEmergências, e atualmente as ambulâncias do Samu são tripuladas por militares da corporação. 0 Serviço deAtendimento M óvel deU rgência atendeàs chamadas domiciliares, e os Bombeiros às de via pública; porém, beneficiadas pela articulação, as duas equipes são capacitadas para todos os tipos de atendimento. Prevalece o critério de presteza, atuando a equipe que estiver mais próxima do local de ocorrência. A equipe do Samu do Rio era composta por 73 médicos, 151 enfermeiros e 278 técnicos/auxiliares de enfermagem.

Como se vê, arranjos diversificados demarcam a relação entre essas duas instituições. Pontuou-se em depoimentos o sentido de aprender a conviver, a superar divergências e a agregar 
esforços para se realizar um atendimento me Ihor à população.

$M$ uitas vezes a gente entra em conflito com os Bombeiros; eles não aceitam perder esta função. Eles chegam nos acidentes, não pedem apoio da ambulância USA, que teria um médico que poderia fazer um atendimento mais especializado. Então aos poucos está melhorando, mas ainda existe confli to com o Corpo de Bombeiros, que vai para o atendimento e não solicita apoio (profissional do pré-hospitalar móvel/M anaus).

\section{0 atendimento pré-hospitalar fixo}

As equipes do PSF (posteriormente denominado Estratégia Saúde da Família) das cidades pesquisadas possuem equipes mínimas: agente desaúde, clínico geral etécnico/auxiliar deenfermagem. Também há esforços no Rio e em Recife para incluir novas categorias como odontólogo, nutricionista, assistente social e fonoaudiólogo.

$\mathrm{N}$ as unidades de ABA, observou-se uma diversidade maior de profissionais. Das 22 unidades estudadas, os profissionais mais presentes eram o técnico ou o auxiliar de enfermagem, agentes de saúde, auxiliar de serviços administrativos e de serviços gerais, técnico/auxiliar de laboratório, enfermeiro, médicos (destacava-se o clínico geral emergencista) e odontólogo. M anaus apre sentava, na totalidade das 14 unidades, 71 médicos, 41 enfermeiros, 213 técnicos/auxiliares de enfermagem, 31 assistentes sociais e apenas cinco psicólogos, um fonoaudiólogo, um terapeuta ocupacional (TO). Destacava-se por dispor de 38 odontólogos e 35 bioquímicos. Brasília, em suas cinco unidades, e Rio de Janeiro, nas suas três, possuíam, respectivamente, 52 e 12 médi$\cos , 29$ e dois enfermeiros, 11 e dois odontólogos, nove e seis assi stentes so ciais, zero e seis psicólogos, zero e dois fonoaudiólogos, dois e zero TO, 36 ezero técnicos/auxiliares de enfermagem. Nenhuma das duas cidades possuía, nestes serviços, técnicos de radiologia. Chama a atenção a ausência ou o pequeno número de profissionais nos serviços do Rio.

Em todos os PS 24 horas pesquisados, a equipe básica era composta por técnico ou auxiliar de enfermagem, médico clínico geral emergencista, auxiliar de serviços administrativos e de serviços gerais, técnico ou auxiliar de laboratório, enfermeiro, odontólogo e técnico de radiologia. Destacam-se duas unidades de Brasília que registraram equipe profissional composta apenas de técnico ou auxiliar de enfermagem e de laboratório, auxiliar de serviços administrativos e enfermeiro. Nas outras cidades, esses serviços apresentaram maior diversidade. Novamente destaca-se o elevado número de odontólogos, bioquímicos e auxiliares de serviços gerais, administrativos e de enfermagem de $M$ anaus.

São raros os serviços de referência para atender idosos no PH fixo. Recife é a capital com o maior número deles, sete ambulatórios especializados, talvez pela expressiva participação dos idosos na sua população. O Rio de Janeiro tinha um desses ambulatórios, com a retaguarda da Universidade Aberta da Terceira Idade (Unati), da Universidade do Estado do Rio de Janeiro (U erj). Contudo, esse serviço padecia da pouca oferta de vagas na rede para atender aos idosos, gerando uma procura muito além da sua capacidade de absorção.

Entrevistados de $M$ anaus percebem considerável avanço na disponibilidade de serviços para atender ao idoso. Citam os Centros de Atenção Integral à Melhor Idade (Caimi), um posto de saúde especializado, o Parque M unicipal do Idoso, além de 150 grupos de idosos cadastrados que realizam atividades de apoio psicossocial.

0 atendimento

aos idosos vítimas de violências

Quase metade dos serviços pré-hospitalares prestava suporte ou acompanhamento aos idosos vítimas de acidentes e violência. Entretanto, apenas 32,5\% deles ofereciam atendimento à família das vítimas (Tabela 1).

Atender ao agressor é tarefa difícil, mas necessária, principalmente nos casos de violência intrafamiliar, tão frequente entre pessoas idosas. Apenas $13,7 \%$ dos serviços pré- hospitalares aqui estudados faziam acompanhamento aos autores de violência, com destaque para o PSF, que está mais próximo das dinâmicas familiares pelas características do atendimento prestado.

Quase 28\% das unidades pesquisadas apoiavam as equipes que trabalham no atendimento das situações de violência contra os idosos, mas apenas $12,5 \%$ dos profissionais desses serviços consideraram que esse suporte é adequado e somente $10 \%$ disseram que eleésuficiente.

Chama a atenção o elevado número de todas as modalidades de serviços que não informaram acerca da adequação eda suficiência das ações de atendimento. Essa omissão pode ser pelo fato de os respondentes desconhecerem a realidade dos seus serviços ou pela avaliação negativa que podem ter, preferindo se calar.

Para tais questões elaborou-se 0 indicador "Proporção deunidades/serviços, exceto móveis, que oferecem de forma adequada e suficiente 
suporte e/ou acompanhamento aos idosos vítimas de acidentes e violências, às famílias/cuidadores de idosos vítimas de acidentes e violências, aos autores de violências contra idoso e às equipes que realizam 0 atendimento". A penas um serviço de $M$ anaus e outro do Rio afirmaram realizar pelo menos duas dessas ações, revelando baixo desempenho das unidades pesquisadas.

A Política Nacional de Redução da Morbimortalidade por Acidentes eV iolências ${ }^{8}$ preconiza a organização dos serviços para o diagnóstico dos acidentes e violências com atendimento resolutivo desde os primeiros níveis da atenção. Entretanto, a prevenção e a identificação dos casos de pessoas idosas vítimas de acidentes e violências são pouco realizadas (Tabela 2). O bserva-se exceção nas equipes do PSF de Manaus, queem sua totalidade afirmam realizar tais ações. No outro extremo estão os quatro PS e o PH móvel de Recife, quenão fazem identificação nem prevenção dos acidentes e violências.

A prevenção constitui uma das diretrizes da PNRM AV. Por isso elaborou-seo "Índicedeações de prevenção de acidentes eviolências", formado pela "proporção de unidades/serviços que reali- zam ações de preven ção de violências e ações voltadas para prevenção deacidentes no domićlio e nas vias públicas". Considerando-se a realização de ações de prevenção tanto das violências como dos acidentes, verificou-se queapenas $45,5 \%$ dos serviços do Rio de Janeiro, 37,5\% dos de $\mathrm{Ma}$ naus, $12,5 \%$ dos instalados em Curitiba e 11,1\% dos de Recife responderam positivamente. $\mathrm{Ne}$ nhuma das unidades pesqui sadas de Brasília desenvolve simultaneamente as duas ações, e apenas $33,3 \%$ realiza uma delas.

As unidades que responderam sobre ações para identificação dos casos de pessoas idosas vítimas de violências e acidentes informaram ter instrumento de identificação e notificação dos casos, estar integradas com o serviço social e psicologia (Brasília); capacitar profissionais que prestam 0 atendimento (Curitiba); fazer consulta, visita domiciliar, avaliação na comunidade, entrevistas com ação social, orientações, encaminhamentos eidentificação dos casos pelo ACS que os encaminha para a UBS (M anaus). Essas ações também são efetuadas durante as visitas domiciliares (Recife) e realizadas com apoio de instrumentos de avaliação funcional (Rio de Janeiro).

Tabela 1. Distribuição das unidades/serviços das cinco capitais segundo suporte e/ou acompanhamento por modalidade de atendimento pré-hospitalar.

\begin{tabular}{|c|c|c|c|c|c|c|}
\hline Suporte e/ou acompanhamento & $\begin{array}{c}\text { Pré- } \\
\text { hospitalar } \\
\text { móvel } \\
\mathrm{N}=6\end{array}$ & $\begin{array}{c}\text { Unidade da } \\
\text { Estratégia } \\
\text { Saúde da } \\
\text { Família } \\
\mathrm{N}=15\end{array}$ & $\begin{array}{c}\text { Unidade } \\
\text { de atenção } \\
\text { básica } \\
\text { ampliada } \\
\mathrm{N}=22\end{array}$ & $\begin{array}{c}\text { PS/ } \\
\text { Atendimento } \\
24 \mathrm{~h} \\
\mathrm{~N}=22\end{array}$ & $\begin{array}{c}\text { Ambulatório } \\
\text { especializado } \\
\text { N }=15\end{array}$ & $\begin{array}{l}\text { Total } \\
\mathrm{N}=80\end{array}$ \\
\hline \multicolumn{7}{|l|}{ Oferece } \\
\hline Aos idosos vítimas de acidentes e violência & 5 & 12 & $10(1)$ & 11 & 5 & 43 \\
\hline $\begin{array}{l}\text { Às famílias de idosos vítimas de acidentes } \\
\text { e violência }\end{array}$ & 2 & 9 & $5(1)$ & 6 & 4 & 26 \\
\hline Aos autores de violência contra idosos & 1 & 7 & $2(1)$ & 1 & 0 & 11 \\
\hline Às equipes que realizam 0 atendimento & 6 & 6 & $4(2)$ & 5 & 1 & 22 \\
\hline \multicolumn{7}{|l|}{ Adequado } \\
\hline Aos idosos vítimas de acidentes e violência & $3(1)$ & $3(5)$ & $5(14)$ & $8(8)$ & $0(5)$ & 19 \\
\hline $\begin{array}{l}\text { Às famílias de idosos vítimas de acidentes } \\
\text { e violência }\end{array}$ & $1(3)$ & $3(5)$ & $2(18)$ & $4(9)$ & $0(4)$ & 10 \\
\hline Aos autores de violência contra idosos & $1(3)$ & $4(5)$ & $1(19)$ & $1(14)$ & $0(7)$ & 7 \\
\hline Às equipes que realizam o atendimento & 5 & $2(6)$ & $1(17)$ & $2(13$ & $0(7)$ & 10 \\
\hline \multicolumn{7}{|l|}{ Suficiente } \\
\hline Aos idosos vítimas de acidentes e violência & $5(1)$ & $1(5)$ & $1(15)$ & $4(9)$ & $0(5)$ & 11 \\
\hline $\begin{array}{l}\text { Às famílias de idosos vítimas de acidentes } \\
\text { e violência }\end{array}$ & $1(3)$ & $2(5)$ & $0(16)$ & $1(10)$ & $0(5)$ & 4 \\
\hline Aos autores de violência contra idosos & $1(3)$ & $2(5)$ & $0(19)$ & 1 (14) & $0(7)$ & 4 \\
\hline Às equipes que realizam 0 atendimento & 5 & $1(6)$ & $0(17)$ & $2(13)$ & $0(7)$ & 8 \\
\hline
\end{tabular}

*Os números entre parênteses representam os missings decada modalidade de unidade/serviço; 0: informado pela unidade/serviço quenão ofereceo atendimento. 


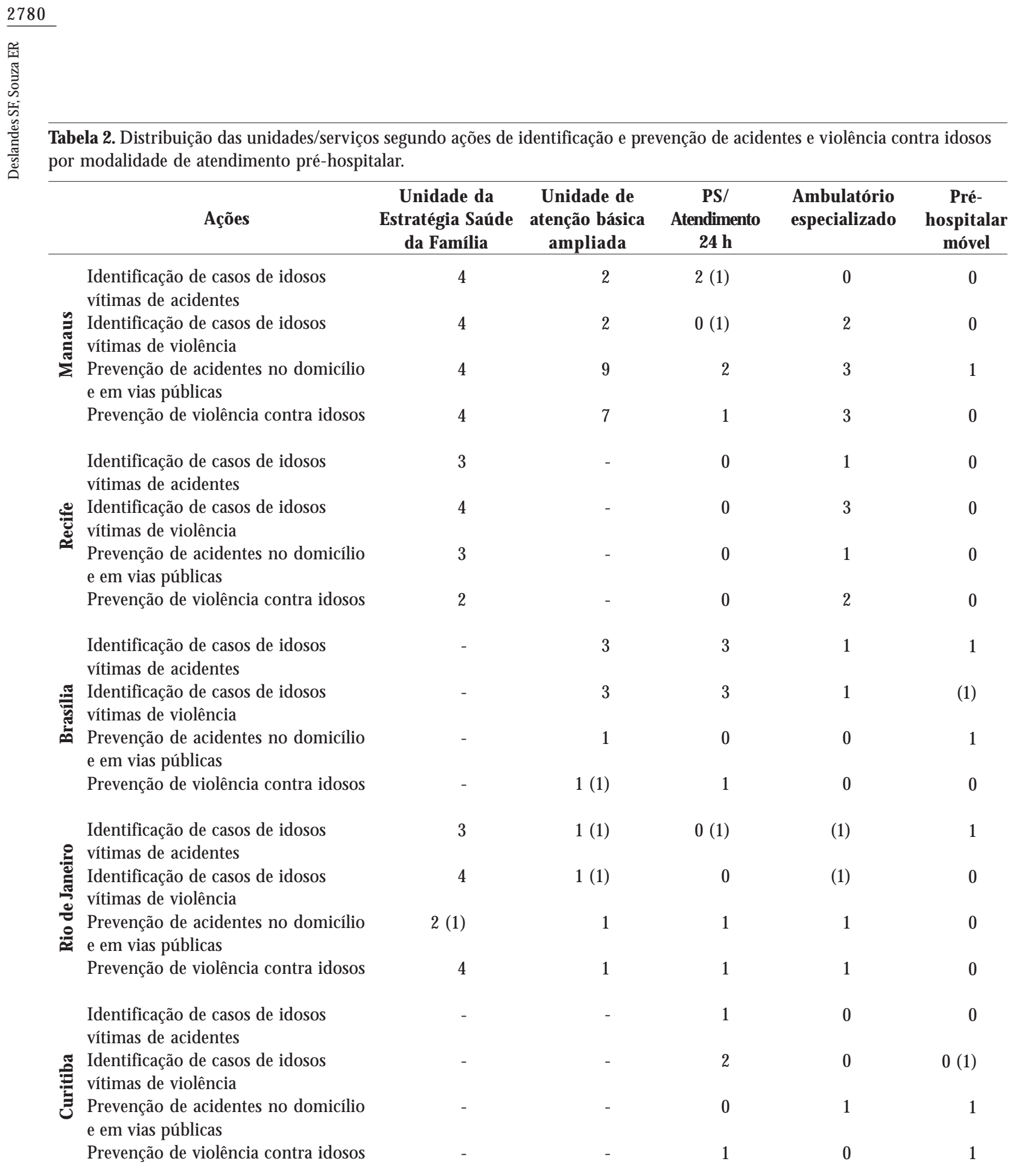

Obs.: Osnúmeros entre parênteses representam os missings decada modalidadedeunidade/serviço; -: sem registro para o item; 0: informado pela unidade/ serviço quenão realiza a ação.

As ações para identificação de casos de idosos vítimas de violência citadas são: avaliação do caso e capacitação dos profissionais que prestam 0 atendimento (Curitiba); denúncia, visita domiciliar, consulta com o serviço social ( $\mathrm{Ma}$ naus); visitas domiciliares, palestras e, no caso de denúncia de maus-tratos, a orientação sobre direitos, além do estímulo ao diálogo com a fa- mília e, se possível, com o agressor (Recife); e utilização de instrumentos de avaliação de risco durante a anamnese (Rio de Janeiro).

Segundo os entrevistados que trabalham no PH móvel, a chamada para atender a um idoso vítima de violência geralmente parte de algum vizinho que, compadecido da situação, aciona o pedido. 
Embora reconheçam os maus-tratos como problema muito relevante, nem sempre os serviços contam com equipes de PH móvel capacitadas para identificar eatuar nesses casos. Tal abordagem só acontece se houver na equipe alguém sensível ao tema.

Porque violência interpessoal não é só bater, é você ver aquele idoso dentro de um quarto escuro, fechado, sem janela equea família vive da aposentadoria dele, o mau-trato, o abandono daquele que seria um incapaz, seria atéum problema legal, porque é um crime, infelizmente não há um treinamento específico, infelizmentevai depender da sensibilidade de quem esteja atendendo a esse idoso. $\mathrm{Na}$ maioria das vezes esta nuance nunca é vista (gestor do Pré-hospitalar/Recife).

Alguns entrevistados já tiveram experiências de aten dimento a idosos que sofreram violências físicas enegligências. Um deles revela a complexa abordagem a alguém que foi agredido por um membro da família:

Esse idoso que eu atendi fez a queixa, estava na delegacia com todo o aparato, sofreu um trauma facial e levamos ele para o hospital, demos toda a assistência, fizemos 0 curativo e encaminhamos ele para o hospital, mas ele sempre na retranca, não informando quem era o agressor, com temor de ter alguma reação (profissional do pré-hospitalar/Recife).

Segundo depoimentos, na maioria desses casos a violência é tratada como um trauma cuja assistência seguirá o protocolo do Advanced Trauma Life Support (ATLS).

Q uando étrauma a gente segue o protocolo do ATLS, são rotinas que são seguidas por qualquer paciente vítima de trauma (profissional do pré hospitalar/M anaus).

As equipes revelam ter muitas dúvidas sobre como proceder ea quem notificar as situações de violências contra idosos.

Aqui em M anaus tem essa delegacia específica do idoso, talvez seja o caso de denunciar pra essa delegacia, se a gente notar que o paciente foi vítima de violência e encontrar o suspeito (profissional do pré-hospitalar/M anaus).

Esse entrevistado considera que nos casos de violência contra criança já existe uma rede de notificação queinclui os hospitais de emergência e conselhos tutelares, mas isso não ocorre em relação ao idoso.

Diante de tantas dúvidas, o profissional do PH móvel parece se ater ao registro do atendimento ecomunicar ao hospital onde o pacienteé entregue:

A gentenão faz nada, a gentesó relata no nosso prontuário, na nossa fichinha, passa pro médico plantonista e chama a assistência social do hospital pra ela tomar as providências (profissional do pré-hospitalar/Rio de Janeiro).

Excepcionalmente, alguns profissionais relatam queidentificam negligências severas aos cuidados do idoso e fazem a notificação.

A paciente estava com essas escaras na cara, tinha umas equimoses, como se tivesse sido apertada, pega com força, emagrecida, desnutrida, desidratada, acabada realmente. E relatei na época, me lembro que relatei "paciente vítima de maustratos", eu coloquei isso mesmo. Bem, isso foi parar no M inistério Público [M P], não, a gente teve que responder na Delegacia e aí o M P entrou também, foi através da Secretaria da Saúde (profissional do pré-hospitalar/Rio de Janeiro).

Certos profissionais, por iniciativa própria, sem nenhuma capacitação, orientam a família ou chamam a sua atenção quanto à negligência praticada.

Entrevistados dos serviços PH fixo revelam que o primeiro obstáculo na identificação de maus-tratos refere-se à dinâmica familiar. Relatam que é usual o idoso sentir-se envergonhado de revelar a situação ou tentar proteger o filho/ filha ou outro cuidador da responsabilidade pelas violências praticadas. 0 quadro se agrava quando o idoso é o cuidador de um usuário de drogas ou portador de transtorno mental. Após transpor a vergonha ou negação da situação, os profissionais tentam negociar alternativas e reforçar a perspectiva dos direitos dos idosos. Essas não são tarefas fáceis, mas necessárias para 0 reconhecimento da autonomia dos idosos.

A delicadeza necessária para esseacolhimento e escuta qualificada torna-se inviável quando o profissional de saúde dispõe de pouco tempo. Assim, as situações maisfacilmentenotificadas referem-se à negligência dos cuidados, especialmente quando o idoso apresenta perda de autonomia (quadros de transtornos, demências), pois aí o profissional evoca a questão da perda de capacidade.

0 fluxo de atendimento dos idosos e de notificação dos maus-tratos ainda não foi estabelecido na totalidade dos serviços visitados. Identificadas as situações de violência, dois cenários são mais comuns: 0 encaminhamento ao M inistério Público (MP), com acompanhamento pelo serviço ( $M$ anaus e Braślia), e a inércia, ora pelo desconhecimento sobre como agir, ora pela constatação da baixa resolutividade do sistema.

Um profissional relatou que, além dos procedimentos oficiais, busca-se orientar as famílias sobre a violência contra idosos. Segundo ele, há diversas situações de maus-tratos (especialmentenegligência) no cotidiano do serviço, e a famí- 
lia é convocada para sensibilizações e trabalhos educativos.

Em Curitiba, o Serviço de Referência recebia chamadas do M P para atendimento e averiguação de maus-tratos. Todavia, por constituir o único serviço especializado na atenção ao idoso, não conseguia absorver toda a demanda. Diante de uma suspeita, buscava envolver a equipe (geriatra, médico, assistente social). A assistente social realizava o histórico e tomava as medidas. Geralmente, a família era chamada para verificar se as queixas do idoso eram reais ou fantasiosas em razão de diagnósticos de transtornos mentais. Nem esses serviços possuíam uma ficha de notificação, nem adotavam a do Ministério de Saúde. As medidas iniciavam orientando-se o idoso a buscar a procuradoria.

M uitas das vezes 0 idoso é orientado a procurar a procuradoria de defesa dos direitos da pessoa idosa, queé aqui nas proximidades. A gente argumenta soluções direitas, argumenta sobre a existência do Estatuto do I doso, al guns dizem que vão, outros não vão, voltam com a mesma queixa ( profissional do préhospitalar/Curitiba).

Em M anaus, poucas unidades possuíam protocolos clínicos para atendimento de idosos vítimas de acidentes e violência: uma unidade do PSF, quatro das 14 unidades de ABA, um dos cinco ambulatórios especializados eo PH móvel. Em Recife, somente o serviço de resgate tem o protocolo. Em Brasília, essa especificidade do atendimento era encontrada em uma unidade de ABA eem um PA 24 horas; no Rio de Janeiro, em apenas uma unidade deABA eno PH móvel. Por fim, em Curitiba, esses protocolos faziam parte da rotina dedois PS edeum dos dois PH móveis.

\section{Articulação inter e intrassetorial}

A integração com outras áreas éfundamental quando se trata de atender a situações de violência. Embora seja uma recomendação de diversos autores, esse ainda é um desafio para os serviços de PH móvel de Manaus e do Rio de Janeiro e também para 0 ambulatório especializado dessa última cidade. A Tabela 3 mostra o número de equipes que informaram ter integração com as mais diversas áreas afins para esse tipo de atenção. É bom destacar quea ação social $(67,5 \%)$ ea justiça $(48,7 \%)$ são as áreas mais citadas pelas unidades estudadas. Poucos trabalham conjuntamente com o setor de turismo e lazer: 16,2\% e $18,7 \%$ dos serviços, respectivamente.

A proximadamente $76,5 \%$ dos serviços pesquisados informaram receber pacientes de outras unidades de saúde, eem $68,7 \%$ deles os pacientes vêm encaminhados pelo PSF ePacs. Asáreas ou instituições das quais as unidades de $\mathrm{PH}$ menos recebem encaminhamentos são as organizações não governamentais ( O G Gs) e os hospitais psiquiátricos (Tabela 4). N oventa por cento das unidades encaminham os idosos para outros serviços de saúde, e 77,5\% para hospitais gerais. Os locais para onde há menos encaminhamentos são as ONGs, o M P e as delegacias.

A análise qualitativa demonstrou que "a mobilização de serviços da rede de saúde, suporte social e defesa dos direitos dos idosos" para o

Tabela 3. Distribuição das unidades/serviços segundo integração com outras áreas por modalidade de atendimento pré-hospitalar.

\begin{tabular}{lcccccc}
\hline \multicolumn{1}{c}{ Áreas } & $\begin{array}{c}\text { Pré- } \\
\text { hospitalar } \\
\text { móvel } \\
\mathrm{N}=6\end{array}$ & $\begin{array}{c}\text { Unidade da } \\
\text { Estratégia } \\
\text { Saúde da } \\
\text { Família } \\
\mathrm{N}=15\end{array}$ & $\begin{array}{c}\text { Unidade } \\
\text { de atenção } \\
\text { básica } \\
\text { ampliada } \\
\mathrm{N}=22\end{array}$ & $\begin{array}{c}\mathrm{PS} / \\
\text { Atendimento } \\
24 \mathrm{~h} \\
\mathrm{~N}=22\end{array}$ & $\begin{array}{c}\text { Ambulatório } \\
\text { especializado } \\
\mathrm{N}=15\end{array}$ & $\begin{array}{c}\text { Total } \\
\mathrm{N}=80\end{array}$ \\
\hline Ação social & 3 & 9 & 15 & $16(1)$ & 11 & 54 \\
Educação & 1 & 9 & 10 & 9 & 3 & 32 \\
Justiça & 3 & 3 & 7 & 15 & 11 & 39 \\
Segurança & 4 & 3 & 5 & 15 & 6 & 33 \\
Esporte & 2 & 7 & 3 & $3(1)$ & 7 & 22 \\
Lazer & 2 & 7 & 10 & $0(1)$ & 5 & 15 \\
Turismo & 2 & 3 & 4 & $0(1)$ & 6 & 13 \\
Direitos Humanos & 2 & 5 & 7 & 10 & 8 & 32 \\
Trabalho & 2 & 3 & 6 & $3(1)$ & 5 & 19 \\
\hline
\end{tabular}

0: informado pela unidade/serviço quenão tem integração com a área. 
acompanhamento dos casos de violências apre senta-se muito precária.

Um entrevistado, vinculado ao $\mathrm{PH}$ fixo do serviço de referência do Rio de Janeiro, referiu o completo descrédito e desânimo quanto à capacidade de as instituições de defesa dos idosos darem respostas efetivas e cobertura suficiente às situações apresentadas:

A lei diz, o Estatuto diz que vocêtem que de nunciar. Existem cinco instâncias pra denúncias: Delegacia do Idoso, Promotoria isso e aquilo, são umas cinco instâncias. A contece que estas instâncias não dão conta, pelo menos aqui no Rio de Janeiro, de dar suporte a isso. Eles têm uma assistente social, meio carro, aquela situação assim que você... você vai lá, você vai dizer ai, ai, não pode fazer isso, e ele continua no mesmo lugar, com o mesmo agressor, na mesma situação de risco (gestor do pré-hospitalar/Rio de Janeiro).

Deste depoimento e de outros se depreendea falta de serviços de suporte, como abrigo em casos de risco ao idoso. Tampouco é possível atualmente contar com uma retaguarda de serviços de apoio à família, o que contribuiria para a prevenção de violências.

A família é obrigada a ficar com o idoso sem que o Estado e o sistema deem um suportea eles. É toma! Fica com paciente acamado, paciente com alta dependência, com uma despesa... um dosgrandes motivos, a meu ver, de vocêter essa situação de esgarçamento da relação, de violência, de agressividade para com a pessoa (gestor do pré hospitalar/Rio de Janeiro).

Tabela 4. Distribuição das unidades/serviços das cinco capitais segundo áreas que recebem e encaminham pacientes por modalidade de atendimento pré-hospitalar.

\begin{tabular}{|c|c|c|c|c|c|c|}
\hline Áreas & $\begin{array}{c}\text { Pré- } \\
\text { hospitalar } \\
\text { móvel } \\
\mathrm{N}=6\end{array}$ & $\begin{array}{c}\text { Unidade da } \\
\text { Estratégia } \\
\text { Saúde da } \\
\text { Família } \\
\mathrm{N}=15\end{array}$ & $\begin{array}{l}\text { Unidade de } \\
\text { atenção } \\
\text { básica } \\
\text { ampliada } \\
\mathrm{N}=22\end{array}$ & $\begin{array}{c}\mathrm{PS} / \\
\text { Atendimento } \\
24 \mathrm{~h} \\
\mathrm{~N}=22\end{array}$ & $\begin{array}{l}\text { Ambulatório } \\
\text { especializado } \\
\qquad \mathrm{N}=15\end{array}$ & $\begin{array}{l}\text { Total } \\
\mathrm{N}=80\end{array}$ \\
\hline \multicolumn{7}{|l|}{ Recebe de } \\
\hline PSF/Pacs & 2 & $11(1)$ & 17 (1) & 16 & 9 & 55 \\
\hline CAPS & 3 & 9 & $4(2)$ & 11 & 8 & 35 \\
\hline Hospitais psiquiátricos & 4 & 3 & $3(2)$ & 8 & 6 & 24 \\
\hline Hospitais gerais & 4 & 4 & $10(2)$ & 11 & 8 & 37 \\
\hline Outras unidades de saúde & 3 & 9 & 18 (1) & 19 & 12 & 61 \\
\hline Ministério Público & 2 & 5 & $7(2)$ & 7 & 11 & 32 \\
\hline Delegacias & 3 & 4 & $5(2)$ & 13 & 9 & 34 \\
\hline Conselhos de direitos & 2 & 4 & $8(1)$ & 8 & 9 & 31 \\
\hline $\begin{array}{l}\text { Secretaria de Desenvolvimento/ } \\
\text { Assistência/Ação Social }\end{array}$ & 2 & 4 & $8(1)$ & 15 & 11 & 40 \\
\hline ONGs & 1 & 2 & $4(1)$ & 8 & 6 & 21 \\
\hline Outros $(*)$ & $1(2)$ & $0(9)$ & $2(13)$ & $2(4)$ & $3(4)$ & 8 \\
\hline \multicolumn{7}{|l|}{ Encaminha para } \\
\hline PSF/Pacs & $1(1)$ & $8(1)$ & $13(1)$ & 14 & 10 & 46 \\
\hline CAPS & $1(1)$ & 13 & $10(1)$ & 14 & 10 & 48 \\
\hline Hospitais psiquiátricos & 5 & 13 & 9 & 17 & 9 & 53 \\
\hline Hospitais gerais & 5 & 15 & 15 & 18 & 9 & 62 \\
\hline Outras unidades de saúde & $5(1)$ & 15 & 20 & 20 & 12 & 72 \\
\hline Ministério Público & $1(1)$ & 9 & 10 & 8 & 11 & 39 \\
\hline Delegacias & $1(1)$ & 11 & 10 & 10 & 7 & 39 \\
\hline Conselhos de direitos & $1(1)$ & 11 & $12(1)$ & 12 & 8 & 44 \\
\hline Secretaria de Desenvolvimento/ & $1(1)$ & 9 & $10(1)$ & $14(1)$ & 10 & 44 \\
\hline Assistência/Ação Social & & 7 & & & & \\
\hline $\begin{array}{l}\text { ONGs } \\
\text { Outros }(*)\end{array}$ & $\begin{array}{l}0(1) \\
0(4)\end{array}$ & $0(6)$ & $\begin{array}{r}6 \\
3(14)\end{array}$ & $\begin{array}{r}10 \\
3(8)\end{array}$ & $\begin{array}{l}5(1) \\
4(3)\end{array}$ & $\begin{array}{l}28 \\
10\end{array}$ \\
\hline
\end{tabular}

* M anaus incluiu Fundação Dr. Thomas; Recife citou demanda espontânea, movimentos sociais, escolas, Samu, U CIS GuilhermeAbath ecentral de emergência; Brasília não informou as outras instituições; Curitiba incluiu casas de repouso; 0: informado pela unidade/serviço quenão encaminha para essas/recebe dessas instituições. 
Teremos que ter lugares para encaminhar idosos em situação de risco para serem abrigados. Então, se hoje eu tenho uma cadeirante sofrendo maus-tratos, que precisa ser tirada do meio familiar, vai ser encaminhada pra onde? (gestor do pré-hospitalar/Curitiba).

Em Curitiba, havia expectativa da criação de centros-dia para atender aos idosos e permitir que seus cuidadores tivessem alguns dias livres. Em Brasília, o grande problema parecia ser a dificuldade de realizar referência e contrarreferência para outros serviços da rede de saúde. Os entrevistados de Curitiba também avaliaram enfaticamente a falta de leitos para idosos ou a seletividade negativa da rede hospitalar para casos de internação:

$\mathrm{Na}$ hora de um médico decidir que uma vaga na UTI é de um adulto, jovem ou idoso, ele vai optar pelo adulto ou jovem, que tem mais viabilidade de sobrevida. Então a gente tem muita dificuldade de internamento (gestor do pré-hospitalar/Curitiba).

M esmo diante desses obstáculos, al guns profissionais avaliaram que hoje há mais recursos jurídicos e de apoio aos direitos dos idosos. E embora identificando a necessidade não atendida de capacitação para atuar pelo novo paradigma, reconhecem avanços em comparação com algumas décadas atrás:

Hoje a política do idoso tem nos ajudado bastante. Eu acho quejá foi muito complicado, muito mais difícil da gente ter acesso na ajuda ao idoso, hoje é muito mais fácil. H oje tem o fórum atuante toda quinta-feira... tem políticas maravilhosas no papel, nem tão maravilhosas na prática.. o próprio idoso hoje tem uma abertura maior. Ele tem consciência, eleanda com o Estatuto na bolsa, mas ainda os profissionais que atuam com idoso precisam ser capacitados (profissional do pré-hospitalar/ $M$ anaus).

\section{Parcerias}

com a rede de serviços de proteção social

A mobilização para se constituir uma rede dos serviços no município para atender aos idosos vítimas de violência variou consideravelmente entre as cidades. M anaus e Curitiba avaliaram de forma muito positiva essa integração, ao contrário dos técnicos cariocas, que foram os mais críticos, e os de Recife e Brasília, que não avaliaram essa questão.

Os profissionais de $M$ anaus avaliaram que a cooperação entre os serviços melhorou consideravelmente nos últimos anos, tornando-se referência para a região. Dizem que o Fórum Perma- nente do I doso possibilitou grandes vitórias como os Caimi. E as parcerias entre o M P ea Delegacia dos I dosos têm se estreitado.

Então nós somos totalmente interligados com todas as instituições que tratam da questão do idoso. Vale ressaltar com o M P etambém com a D elegacia do Idoso. Inclusive estamos trazendo para participar dos nossos grupos de educação em saúde a del egada como forma de divulgação do trabal ho. Nós estamos indo, toda a equipe, visitar a delegacia (gestor do pré-hospitalar/M anaus).

Os entrevistados de Recife e Brasília limitaram-se a citar os encaminhamentos dos casos de violências ao M P pela mediação da assistente social. Em Brasília, foi mencionada parceria com a Secretaria de Direitos $\mathrm{H}$ umanos para a realização de cursos de cui dadores. O s entrevistados de Curitiba apontaram positivamente a parceria com outras instituições para 0 atendimento de idosos em situação de violência. Contudo, poucas instituições foram citadas nos relatos. As denúncias eram formalmentefeitas ao M P por uma psicóloga do serviço, designada para essa tarefa. o SOS Idoso também foi mencionado como elo de suporte para esse atendimento.

No Rio de Janeiro, os entrevistados foram mais céticos ao analisar parcerias para atender às situações de violências. Relataram não haver articulação, apenas procedimentos de encaminhamento. Afirmaram ainda quetentativas para maior aproximação já foram feitas sem êxito.

A gente já participou de simpósios, de mesas, quer dizer, procurando discutir isso com eles, mas não existe nada formal (gestor do PH/Rio de Janeiro).

Eles também criticaram a morosidade das respostas às denúncias feitas ao $M P, 0$ que aumenta consideravel mente o risco dos idosos no ambiente violento. Comentaram também as dificuldades de acesso à Delegacia do I doso.

Delegacia do Idoso, quando acontece, a gente logo liga para saber, pra encaminhar alguém, nos identificar. Esses números nunca atendem. M P, a coisa não é rápida, demora. Pra mim elas são ineficientes, porque quando você trata com violência tem que ter mais preparo, tem que ser uma coisa mais rápida. D eixam [na Delegacia do I doso] mofando, esperando. 0 idoso tem que ser levado, ele não consegue caminhar rápido. O M P demorou, mas demorou muito. N esse caso [que foi encaminhado] esperou um ano, é muito tempo para o filho que era superameaçador, ele podia ter matado essa mãe (profissional do pré-hospitalar/Rio deJaneiro).

Assim, críticas à baixa resolutividade do $M P$ e difícil acesso à Delegacia do Idoso, em termos 
tanto de localização como de disponibilidade de horário de atendimento, além de má acolhida, foram constantes no Rio de Janeiro.

\section{Discussão}

Neste item destacam-se pontos cruciais apontados na análise dos dados deste estudo empírico. Inicialmente, discutem-se questões relativas ao PH móvel, das quais sobressai a desigualdade do tamanho das equipes ea sua falta de capacitação para identificar e atuar nos casos de violência contra os idosos. Basicamente formadas por generalistas, nem sempreel as contam com a necessária especialidade para 0 atendimento dos idosos com quadros mais complexos de saúde. Vários profissionais disseram ter muitas dúvidas sobre como proceder e a quem notificar os casos, embora sejam extremamente qualificados para atender aos traumas, pois tem formação em Advanced Trauma Life Support ${ }^{9}$.

Tais achados são corroborados pela literatura norte-americana, a qual relata que os profissionais desaúdejáatuam nas situações de violência contra crianças, adolescentes emulheres há décadas, mas a abordagem do abuso e negligência em relação à pessoa idosa ainda é recente. Alegam se sentirem inseguros quanto aos procedimentos a serem adotados para identificar, tratar e encaminhar os casos ${ }^{10}$. Q uanto ao atendimento PH fixo, também existem distinções e limitações nas equipes das capitais, em termos detamanho ediversidade de categorias profissionais.

Há carência de uma diretriz efetiva que integre a Estratégia Saúde da Família com os serviços hospitalares, para que os idosos possam ser acompanhados em suas comunidades, após a internação. Esse problema também foi apontado em estudo anterior ${ }^{9}$ que analisou a implantação do PH nessas mesmas cinco cidades alguns anos antes. Embora possuam uma central de re gulação que é positivamente avaliada pelos gestores e profissionais, muitas vezes os serviços $\mathrm{PH}$ não dispõem da retaguarda de leitos hospitalares, o que agrava a baixa articulação entre esses setores do atendimento ${ }^{9}$.

São poucos os serviços do $\mathrm{PH}$ que envolvem a família do idoso ou que fornecem al guma atenção ou orientação a ela. M enor ainda éa proporção daquel es que prestam qual quer atendimento ao autor da agressão. A penas 13,7\% dos serviços aqui estudados dão suporte e acompanhamento aos autores de violência contra idosos. Estas são lacunas que contribuem para uma visão e abor- dagem limitadas, tanto nas ações de atenção como nas de prevenção. E podem ser resultantes da percepção de que este é um problema social ou policial e não um problema relacionado ao campo da saúde ${ }^{10,11}$.

Se as ações de atenção integral à pessoa idosa em situação de violência são incipientes no atendimento PH, os dados aqui analisados demonstram que menos implementadas ainda são as ações de prevenção das distintas formas de violência que acometem esse grupo. $\mathrm{N}$ em metade dos serviços das cidades investigadas realiza ações de prevenção da violência.

Os profissionais reclamam da falta de suporte como formação, supervisão e apoio psicológico; demonstram carência de informaçõese decapacitação, tanto para eles como para os cuidadores formais e informais de idosos para lidarem com os casos de violência. A capacitação tem priorizado o desenvolvimento de habilidade para o tratamento das lesões e pouco enfatiza as dinâmicas da violência responsáveis pelos agravos ${ }^{11}$. No Rio de Janeiro, ébaixa a resolutividadedo M P eédifícil 0 acesso à Delegacia do Idoso. Estudos afirmam a necessidade de amplo e continuado programa de treinamento/capacitação desses profissionais para que reconheçam os sinais e sintomas da violência e o nível de exposição a que eles estão submetidos $^{10}$. Destacam como um desafio para 0 atendimento PH a educação da comunidade para que ela aproveite os ben efícios desses serviços ${ }^{12}$. Consideram crucial a conscientização ea corresponsabilização da população na utilização desses serviços, para que ela reconheça rapidamente as situações que requerem a ativação deles.

A notificação, preconizada pelas políticas dirigidas ao idoso e pelo Estatuto, só é feita excepcionalmente; quando ocorre, o encaminhamento costuma ser feito para o M P. Este órgão, como representantedaJustiça, eos dispositivos da ação/ assistência social são as áreas com as quais os serviços de saúde pesquisados mais se articulam. Entretanto, os fluxos ainda não estão estabelecidose é precária a mobilização da rede deserviços de saúde, suportesocial e defesa dos direitos para acompanhamento dos casos. Concorre para esta situação a falta de retaguarda, como abrigos, a dificuldade de conseguir leito hospitalar e mesmo a resistência à internação de idosos, relatada por alguns profissionais.

A ação denotificar um fato violento tem gerado controvérsias. Por um lado, as leis obrigam e os códigos de ética profissional orientam que ela deve ser feita ${ }^{13}$; por outro, os profissionais, embora afirmem sua importância, deixam de fazê-la 
alegando desconhecimento quanto aos procedimentos, dificuldades para identificar os casos, medo de prejudicar a confiança da relação médico-pacienteeda quebra desigilo profissional, além de terem receio de represálias, tanto em relação a si mesmos como em relação ao paciente ${ }^{14}$.

Fica claro que se a notificação depende das atitudes e habilidades do profissional ${ }^{9}$, ela também é função da estruturação e da organização das redes de aten ção e de proteção. N isto desempenham papel fundamental as articulações e parcerias firmadas. N este estudo, observou-se que a parceria com a rede de serviços local é bastante diferenciada entre as capitais. 0 Rio de Janeiro, por exemplo, reclama da dificuldade de acesso à Delegacia do Idoso e da morosidade do M P.

Conclui-se lembrando os três paradoxos apontados por Rodriguez et al. ${ }^{15}$ sobre a abordagem e a notificação da violência contra a pessoa idosa. Para eles, essas práticas tanto podem

\section{Referências}

1. Brasil. M inistério da Saúde. Política N acional deAtenção às U rgências. Brasília: M inistério da Saúde; 2004.

2. Brasil. M inistério da Saúde. Portaria GM № 1.864 de 29 de setembro de 2003. Política Nacional de Atenção às U rgências. Brasília: M inistério da Saúde; 2004.

3. Champion HR, Copes WS, Sacco WJ, Lawnick M M, Keast SL, Bain Jr. LW et al. The major trauma outcome study: establishing national norms for trauma care. J Trauma 1990; 30:1356-1365.

4. M inayo MCS, Deslandes S, organizadoras. Análise diagnóstica da política nacional de saúde para redução de acidentes e violências. Rio de Janeiro: Editora Fiocruz; 2007

5. M inayo M CS. 0 desafio do conhecimento: pesquisa qualitativa em saúde. 9a ed. rev. aprim. São Paulo: Hucitec; 2006. (Saúde em Debate; 46)

6. Gaskin CJ. Delphi method and nominal group techniques in family planning and reproductive health research; 2003. [site da Internet] [acessado $2007 \mathrm{fev}$ 10]. Disponível em: https://Ira.le.ac.uk/bitstream/ 2381/310/1/The Delphi method revised final.pdf

7. Perry J, Linsley ${ }^{-}$. The use of the nominal group technique as an evaluative tool in the teaching and summative assessment of the inter-personal skills of student mental health nurses. Nurse Educ Today 2006; 26(4):346-353.

8. Brasil. M inistério da Saúde. Portaria n 737 M S/ GM, de 16 de maio de 2001. Política Nacional de Redução da M orbimortalidade por Acidentes e Violências. Brasília: Ministério da Saúde; 2001.

9. M inayo MCS, Deslandes SF. Análise da implantação de atendimento pré-hospitalar móvel em cinco capitais brasileiras. Cad Saude Publica 2008; 24(8):1877-1886. melhorar como podem piorar: (1) a relação mé dico/paciente; (2) a sua qualidade de vida; (3) 0 controle do profissional para decidir o que é melhor para o paciente. Acredita-se que esses paradoxos podem ser superados mediante 0 enfrentamento dos problemas aqui mencionados.

\section{Colaboradores}

SF Deslandes e ER Souza trabalharam na concepção, na análise dos dados e na redação do artigo.
10. Rinker Jr. AG. Recognition and perception of elder abuse by prehospital and hospital-based care providers. Archives of Gerontology and Geriatrics 2009; 48:110-115.

11. Albuquerque VS. Violência sob o olhar e o agir de quem socorre: representações dos profissionais do atendimento pré-hospitalar de urgência e emergência [tese de doutorado em Saúde Pública]. Rio de Janeiro: Escola Nacional de Saúde Pública Sergio Arouca, Fundação Oswaldo Cruz; 2010.

12. Vieira CMS, M ussi FC. A implantação do projeto de atendimento móvel de urgência em Salvador/ BA: panorama e desafios. Rev Esc Enferm USP 2008; 42(4):793-797.

13. Saliba O, Garbin CAS, Garbin AJI, Dossi AP. Reponsabilidade do profissional de saúde sobre a notificação de casos de violência doméstica. Rev Saude Publica 2007; 41(3):472-477.

14. Taylor DK, Bachuwa G, Evans J, Jackson-Johnson V. Assessing barriers to the identification of elder abuse and neglect: a communitywide survey of primary care physicians. Journal of the National M edical Association 2006; 98(3):403-404.

15. Rodríguez MA, Wallace SP, Woolf NH, Mangione CM . M andatory reporting El Elder abuse: between a rock and hard place. Annals of Family M edicine 2006; 4:5-58.

Artigo apresentado em 07/05/2010

Aprovado em 21/05/2010 